\title{
Monitoring eye movements while studying the effects of response familiarization on paired-associate learning'
}

\author{
T. E. MOORE ${ }^{2}$ AND P. D. MCCORMACK, DEPARTMENT OF \\ PSYCHOLOGY, CARLETON UNIVERSITY, Ottawa, Canado
}

Three groups of $S s$ were required to learn a 10-item PA list subsequent to relevant response pretraining (Group $R$ ), irrelevant pretraining (Group IRR) and no pretraining (Group N). Eye movements were monitored during the first 6 of 12 PA trials. Ss of Group $R$ showed superior learning, and an earlier convergence of response and stimulus fixation functions than either of the other two groups. All Ss exhibited a transition from $S-R$ to $S-R-S$ viewing as learning progressed. These findings were discussed in the light of a two-stage notion of verbal PA learning.

It follows from the two-stage conceptualization of verbal paired-associate (PA) learning (e.g., Underwood, Runquist, \& Schulz, 1960) that an experimentally induced increase in response availability should accelerate the response consolidation stage. One way of making responses more available, and thereby facilitating PA acquisition, is to employ a response familiarization procedure. Goss \& Nodine (1965), in their review of the pretraining literature, have pointed out that the findings have been by no means unequivocal. A study by Blanchard (1967), however, employing low association-value trigrams as responses and two-syllable low-similarity adjectives as stimuli, demonstrated clear-cut facilitative effects following 20 response familiarization trials. In the present study an attempt was made to replicate, as closely as possible, the procedure of Blanchard, where three groups were given relevant response pretraining (Group $R$ ), irrelevant pretraining (Group IRR) and no pretraining (Group N).

A recent series of studies (e.g., McCormack \& Haltrecht, 1966), where eye movements were monitored during the learning of PA lists by the study-test method, has produced findings not inconsistent with the two-stage notion. During early trials, Ss viewed the response more than the stimulus while looking first to the stimulus and then to the response. As learning progressed, the stimulus came to be viewed more than the response, with Ss exhibiting a pattern of looking first to the stimulus then to the response and than back to the stimulus. In the present study it was predicted that, because of the greater availability of the responses for Ss of Group R, response-viewing would decrease and stimulusviewing increase at a more rapid rate over trials for these $S s$ than for those of either Group IRR or Group N. Since the stimuli were highly meaningful and the responses were of low $\mathrm{m}$, and since low $\mathrm{m}$ materials evoke prolonged viewing (McCormack \& Hannah, 1967; McCormack \& Moore, in press), no predictions could be made regarding stimulus and response fixation function crossover during the early learning trials of eye movement monitoring. Should disproportionate stimulus viewing develop, however, it would be most probable for Ss of Group R.

Subjects and Apparatus

The Ss were 24 male and 21 female students of introductory psychology. All attempted to learn the same 10-item list and, with one exception, the PA materials were identical to those of Blanchard. The exception involved the substitution of the pair FAITHFUL-RIX for FAITHFUL-FUB, because of the formal similarity introduced by the common initial letters of the latter. Stimuli were low-similarity familiar adjectives (Underwood \& Goad, 1951) while responses were trigrams ranging in associationvalue (Glaze, 1928) from $0 \%$ to $20 \%$ with a mean of $13 \%$. The irrelevant trigrams of Group IRR had an association-value range from 0 to $33 \%$ with a mean of $13 \%$.

The PA list was projected by means of slides to a screen $1.4 \mathrm{~m}$ from $S$ and $2.4 \mathrm{~m}$ from the projector. Three different random list orders were employed, with a 2 -sec presentation rate and a 4-sec intertrial interval. A 1-min rest was introduced at the end of the third trial to enable $E$ to change film. All $S$ were given 12 study-test trials, with only the first six being photographed.
Eye movements were recorded by means of a head-mounted eye-marker camera (Mackworth \& Thomas, 1962) consisting of a 2 $x 8 \mathrm{~mm}$ motion picture unit filming at a speed of 16 frames $/ \mathrm{sec}$, with a periscope that transmits a spot of light reflected from the cornea to the film. The film, when developed, shows the PA slides and, superimposed upon each, a bright circular spot indicating the approximate position of actual fixation. The films were analyzed frame by frame by examining the $S-R$ slides through a film-viewer. Procedure

Familiarization. Fifteen Ss were randomly assigned to each of the three groups, with one $S$ later being dropped from Group $R$ because of film spoilage. Group $R$ received 20 presentations of each of the 10 relevant response items, Group IRR had 20 exposures of each of 10 irrelevant items, while Group $\mathrm{N}$ received no familiarization. The familiarization trigrams were presented in six different random orders by means of a Hull-type memory drum at a 2-sec rate with a 4-sec intertrial interval. Ss were required to spell each trigram aloud and were told that test trials would later be given. Following the 10th familiarization trial, an omitted-elements test was administered, where each trigram appeared for $2-\mathrm{sec}$ with either the first or last letter missing, and S being instructed to complete the item. A free recall test was given following familiarization, at which time $S$ was told to write down as many of the trigrams as possible.

$P A$ Learning. Prior to the PA task, $\mathrm{S}$ was seated in a dental chair and standard learning instructions were presented by means of a tape recorder. $S$ was then told that there would be some apparatus on his head, a description of which would be given at the end of the experimental session. The camera was then placed in position, calibrated, and the task initiated. To control for possible changes in camera speed, an equal number of Ss from each group was processed each day.

Results and Discussion

There were no statistically dependable differences between Groups $R$ and IRR during familiarization on either the omitted-

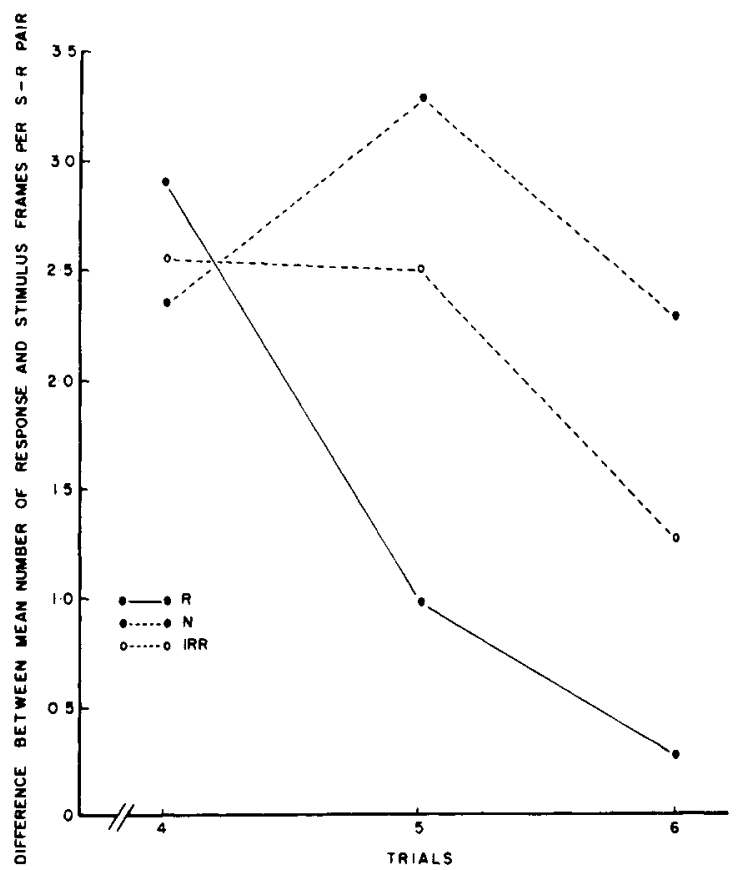

Fig. 1. Difference between mean number of response and stimulus frames per S-R pair as a function of trials 4-6 for Groups R, IRR, and N. 
elements test or on the test of free recall. The mean number of correct responses for omitted-elements for Groups $R$ and IRR, respectively, were 6.20 and $6.00(t=0.93, \mathrm{df}=28, \mathrm{p}>.30)$, while for free-recall, the means were 7.20 and $6.33(\mathrm{t}=1.47, \mathrm{df}=28$, $\mathrm{p}>.10$ ). A one-way ANOVA of mean number of correct responses during the 12 trials of $P A$ learning revealed superior performance on the part of the Ss of Group R $(F=22.04$, df $=$ $2 / 42, p<.001)$. Statistically reliable differences existed between Group $R$ and each of the other two groups $\left(t_{I R R}=4.99 . \mathrm{df}=42\right.$, $\mathrm{p}<.001 ; \mathrm{t}_{\mathrm{N}}=6.31$, $\mathrm{df}=42, \mathrm{p}<.001$ ), while no dependable differences were found between groups IRR and $\mathrm{N}(\mathrm{t}=1.33, \mathrm{df}=$ $42, p>.10$ ). These findings support those of Blanchard and thereby strengthen the existing evidence for the facilitative effects of response familiarization on subsequent PA acquisiton.

The mean number of frames of fixation of the stimulus and of the response were determined for each $S$ for trials 1 to 6 . An ANOVA was performed on these data with Groups as a betweenSs variable and Trials and Conditions ( $S$ vs $R$ fixations) as within-Ss variables. As predicted there was a Conditions effect ( $F$ $=67.96, \mathrm{df}=1 / 41, \mathrm{p}<.001$ ), which reflected a preponderance of response-viewing on the part of all Ss. A statistically dependable Trials by Conditions interaction was also revealed $(\mathrm{F}=2.40, \mathrm{df}=$ $5 / 205, p<.05$ ), which reflected the predicted convergence over trials of the stimulus and response fixation functions. An ANOVA was performed on the data of each of the three groups separately over trials 4,5 , and 6 , where the convergence of the functions was most prominent, the only statistically reliable Conditions by Trials interaction being obtained for Ss of Group $R(F=4.45, \mathrm{df}=2 / 26$, $\mathrm{p}<.025)$. These data, then, were consistent with the prediction that a more rapid degree of comvergence would be observed for those Ss who had relevant response pretraining. The difference between mean number of response and stimulus frames per S-R pair was calculated for trials 4,5 , and 6 , and these data are presented in Fig. 1. Examination of this figure reveals the diminishing difference over trials between stimulus and response viewing on the part of all Ss, with this phenomenon being most pronounced for Ss of Group R.

The overall ANOVA also revealed a statistically reliable Trials effect $(F=7.25, \mathrm{df}=5 / 205, \mathrm{p}<.001)$, this decrease over trials in total viewing time being primarily due to increased eye movement, a phenomenon consistently observed in previous investigations. This transition from S-R to S-R-S viewing was demonstrated to be dependable for all three groups $(F=9.50, \mathrm{df}=5 / 205, \mathrm{p}<.001)$.
Although Ss of Group R exhibited an earlier transition, as would be predicted, this observation was not substantiated statistically. A phenomenon observed in previous studies (e.g., McCormack, Hannah, Bradley, \& Moore, 1967), and one which appeared in the present data, was the increased viewing of the response from trials 3 to 4 where a 1-min rest was introduced to enable $E$ to change film. This phenomenon has been consistently associated in the past with the employment of low $m$ response items, the implication being that response consolidation is incomplete at the time of the film change whenever low $m$ items are employed.

\section{REFERENCES}

BLANCHARD, R. J. Response familiarization and paired-associate learning. J. verbal Learn. verbal Behav., 1967, 6, 668-671.

GLAZE, J. A. The association value of nonsense syllables. J. genet. Psychol, $1928,35,255-269$.

GOSS, A. E., \& NODINE, C. F. Paired-associates learning. New York: Academic Press, 1965.

MACKWORTH, N. H., \& THOMAS, E. L. Head-mounted eye-marker camera. J. Opt. Soc. Amer., 1962, 52, 713-716.

McCORMACK, P. D., \& HALTRECHT, E. J. Monitoring eye movements under two conditions of presentation of paired-associate materials. Canad. J. Psychol, 1966, 20, 154-159.

McCORMACK, P. D., \& HANNAH, T. E. Monitoring eye movements during the learning of high and low meaningfulness paired-associate lists. Psychon. Sci., 1967, 8, 443-444.

McCORMACK, P. D., HANNAH, T. E., BRADLEY, W. J., \& MOORE, T. E. Monitoring eye movements under conditions of high and low intralist response (meaningful) similarity. Psychon. Sci., 1967, 8, 517-518.

McCORMACK, P. D., \& MOORE, T. E. Monitoring eye movements during the learning of low-high and high-low meaningfulness paired-associate lists. J. exp. Psychol., in press.

UNDERWOOD, B. J., \& GOAD, D. Studies of distributed practice: I. The influence of intralist similarity in serial learning. J. exp. Psychol., 1951, 42, 125-134

UNDERWOOD, B. J., RUNQUIST, W. N., \& SCHULZ, R. W. Response learning in paired-associate lists as a function of intralist similarity.J. exp. Psychol, 1959, 58, 70-78.

\section{NOTES}

1. This research was supported by a grant-in-aid from the Associate Committee on Experimental Psychology of the National Research Council of Canada (Grant APA-78) and represents a B. A. (Honours) thesis on the part of the senior investigator.

2. Now at State University of New York, Buffalo. 